\title{
Romanization for a monosyllabic script?
}

The alphabetical system devised for transliterating Chinese charactexs is called romanization. Traditionally, the Wade-Giles system has been most widely accepted by international scholars. However, a new romanized alphabet, pinjin, was officially adopted by China in 1958 and has been increasingly used in classrooms and mass media. This change has had a significant impact in the library world as WadeGiles romanization has been used in cataloging procedures for many decades. In 2000 , the Library of Congress officially adopted the pinyin system and most other libraries have followed suit.

The University of California Irvine ( $\mathrm{GCI}) \mathrm{Li}-$ braries has launched a romanization conversion project. To commemorate this occasion, the East Asian Collection organized an exhibit, which was inspired by noted historian Arnold Joseph Toynbee's work on the merits of ideograms over romanized script.

Toynbee once wrote: " . . by the time that my great-granddaughter who is now aged four or five, reaches my own present age of eightytwo, a drastically reduced and simplified set of the Chinese characters were to have become the worldwide visual code for international communication, just as the so-called Arabic numerals have becone the worldwide code for writing numbers."

He then went on to emphasize the merits of ideograms, i.e, Chinese characters. The popular alphabetical system of writing, because it is based on sounds, rather than semantic concepts has the same limitation that spoken language does: speakers of different languages, or even widely divergent dialects of the same language, often find it difficult or impossible to communicate with each other. Even readers of any single language may have problems in communication clue to changes of pronunciation that have occurred in the course of time. In contrast, Chinese ideograms, because they are independent of pronunciation, provide a mutually comprehensible language for speakers of varied Chinese dialects (the spoken forms of which may not be mutually comprehensible).

Chinese writing, like that of many ancient civilizations, originated in the form of simple pictographs. As the number of characters expanded, new characters were built upon earlier words with the same approximate sound plus the adclition of a categorizing component. While other languages have changed to adopt an alphabetic or syllabic system of writing, at least in part, Chinese people have maintained a tradition of ideograms. A partial explanation could be that Chinese is considered, by and large, a monosyllabic language. In the evolution of the language, the Chinese syllable also has developed an increasingly simple phonetic structure. Except for a few words that begin with vowels, most syllables begin with a consonant or a consonant cluster. The cluster is usually simple, consisting at most of a stop, a fricative, an aspiration, and a semivowel. After the consonant or consonant cluster there is a main vowel, with or without a final consonant or semivowel. The complicated pictographic writing form has become a necessity for a simple phonetically structured language.

In addition to consonants and vowels, there is a third constituent element of the Chinese word. This is the height and movement of the fundamental pitch of the voice, known as tone. Tones have often been described as a device to distinguish otherwise identical words. There are four tones in Mandarin, or Standard Chinese. Local dialects may have a range of five to nine different tones. This feature of tones introduces another dimension of variation in a generally monosyllabic language.

Ideograms, or "square scripts" as Chinese is usually referred to, are particularly well-suited for parallels, couplets, and palindromes in literature. Meanwhile, the monosyllable and tone characteristics may also create short essays with one sound and one rhyme. UCI's exhibit featured examples of classical texts that illustrate characters understandable as written forms, but with content that would be unintelligible if read aloud.

UCI's East Asian Collection organized the exhibit to remind our viewers of the Toynbee theory. We feel romanization is only a temporary substitute for ideograms. Making the original script or character accessible online is our ultimate goal.

\section{Note}

1. Arnold J. Toynbee, Surviving the Future (New York, Oxford University Press, 1971), 102.

- William Sheb Wong, Asian Studies tibrarian, University of California Libraries, Irvine, e-mail: wsuong@uciedu 


\section{An integral piece of your information collection...}

efoumals bibliograpilt

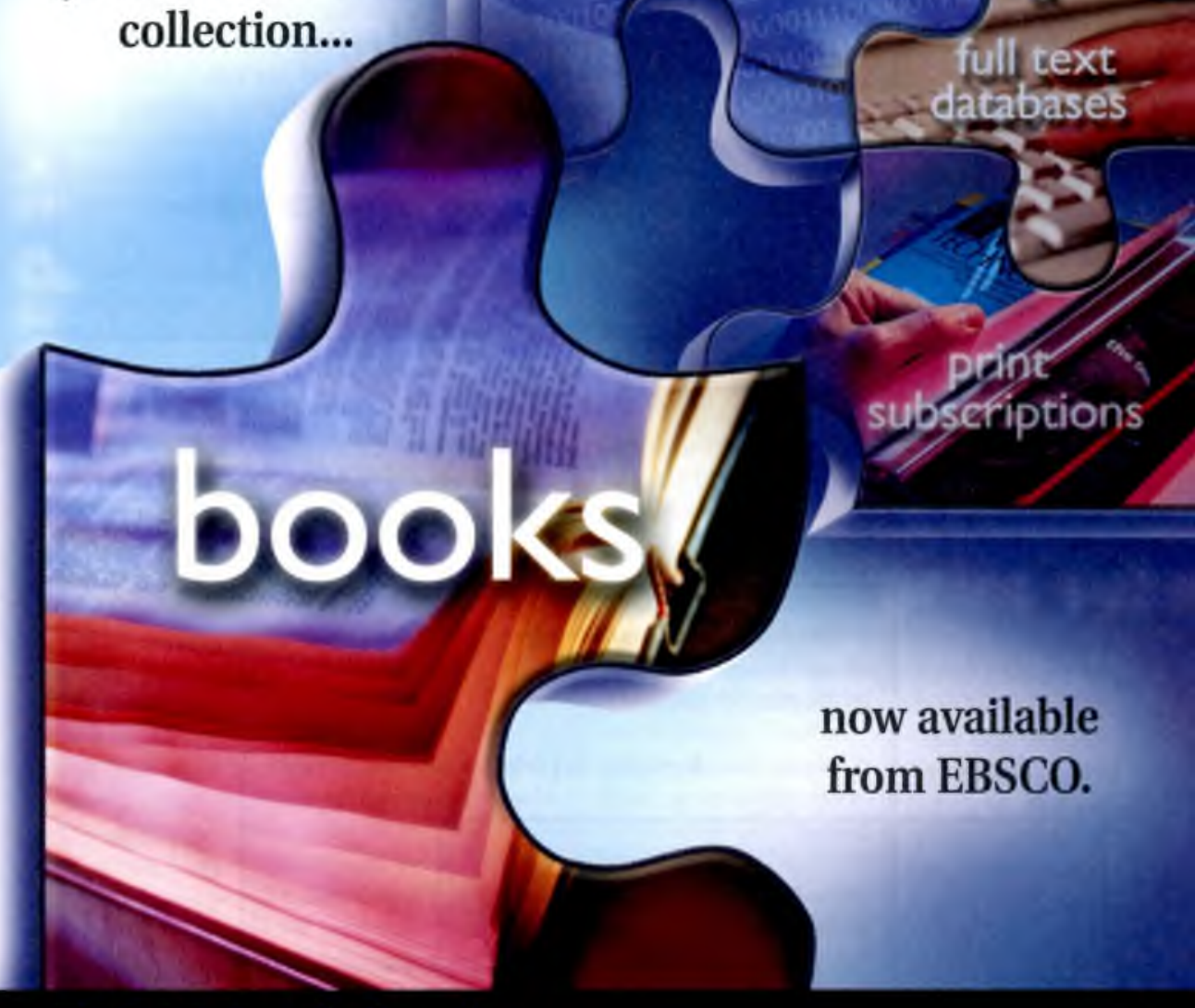

\section{EBSCO Book Services makes book}

procurement easy. The service provides a familiar Web interface for ordering millions of titles, as well as sophisticated administrative features for tracking and managing book purchases.

Users benefit from:

- Competitive pricing on all titles

- Flexible purchase options that allow payment by credit or corporate purchasing card or invoice

- Invoicing and reporting by user, department or organization

- A secure server for all transactions

- An interface that permits end-user customization

- Back-ordering capabilities for books not currently available

- Delivery within 24-48 hours for most locations in the United States.

EBSCO Information Services...bringing together the pieces of your information collection.

\section{For more} information, visit us online at www.ebsco.com. 